\title{
INTERNATIONAL STANDARD PROBLEM 50: THE UNIVERSITY OF PISA CONTRIBUTION
}

\author{
MARCO CHERUBINI*, DAVIDE LAZZERINI, WALTER GIANNOTTI, and FRANCESCO D’AURIA \\ University of Pisa, Largo Lucio Lazzarino 1, 56100 Pisa, Italya \\ *Corresponding author. E-mail : m.cherubini@ing.unipi.it
}

Received July 13, 2012

The present paper deals with the participation of the University of Pisa in the last International Standard Problem (ISP) focused on system thermal hydraulic, which was led by the Korean Atomic Energy Research Institution (KAERI). The selected test was a Direct Vessel Injection (DVI) line break carried out at the ATLAS facility. University of Pisa participated, together with other eighteen institutions, in both blind and open phase of the analytical exercise pursuing its methodology for developing and qualifying a nodalization. Qualitative and quantitative analysis of the code results have been performed for both ISP-50 phases, the latter adopting the Fast Fourier Transfer Based Method (FFTBM). The experiment has been characterized by threedimensional behavior in downcomer and core region. Even though an attempt to reproduce these phenomena, by developing a fictitious three-dimensional nodalization has been realized, the obtained results were generally acceptable but not fully satisfactory in replicating 3D behavior.

KEYWORDS : ISP-50, ATLAS, DVI Line Break, SB-LOCA, APR1400

\section{INTRODUCTION}

The development of the Nuclear Technology with main focus to safety and reliability increase has a strong impact on analytical tools needed to design and/or proof the strength of design solutions. A typical analytical tool involved in this kind of application is the system ThermalHydraulic codes whose development started in early '70s. New features introduced in evolutionary Nuclear Power Plant (NPP) may challenge the capabilities of SYS-TH codes because three dimensional phenomena prediction are nowadays almost essential for correctly reproduce concerned plant behavior attaining to recent NPP generation.

The code capabilities can be effectively tested against a (well designed) experiment carried out in an Integral Test Facility (ITF). Additionally benefits may come if such validation is conducted within an international framework of the International Standard Problems (ISP) promoted and conducted by OECD/NEA.

The present paper deals with the participation of the University of Pisa in the last ISP focused on system thermal hydraulic, which was led by the Korean Atomic Energy Research Institution (KAERI). The selected experiment was a Direct Vessel Injection (DVI) line break carried out at the ATLAS facility. The University of Pisa, along with eighteen other institutions, participated in both blind and open phase of the analytical exercises pursuing its methodology for developing and qualifying a nodalization [ref. 1]. Qualitative and quantitative analysis of the code results have been performed for both ISP-50 phases, the latter adopting the Fast Fourier Transfer Based Method (FFTBM), [ref. 2-3].

\section{OVERVIEW OF ATLAS ISP-50 EXPERIMENT}

\subsection{Description of ATLAS Facility}

The ATLAS is a large-scale thermal-hydraulic integral effect test facility for advanced pressurized water reactors (PWRs). It has been operated in order to investigate major design basis accidents and operational transients for a $1400 \mathrm{MWe}$ pressurized water reactor, APR1400, which was developed by the Korean industry [ref. 4-5]. The ATLAS also incorporates several specific design characteristics of a 1000 MWe-class Korean standard nuclear power plant, OPR1000 (Optimized Power Reactor 1000 $\mathrm{MWe}$ ). It can simulate a wide variety of accident and transient conditions including large and small break LOCAs

The ATLAS is a half-height and 1/288 volume scaled test facility with respect to the APR1400 and it is scaled for full-pressure and full-temperature conditions of the APR1400. The scaling of the ATLAS had been performed according to the three-level scaling methodology [ref. 6]. An important reason for adopting the reduced-height design is to allow the use of an integrated annular downcomer where the multidimensional phenomena can be important in some accident conditions with a DVI operation. A consequence of the reduced height scaling results is the time-reducing results in the model, in fact for the one- 
half-height facility, the time for the scaled model is a square root 2 times faster than the prototypical time. The friction factors and the hydraulic diameter in the scaled model are maintained at the same values as those of the prototype. Figure 1 shows the ATLAS configuration together with its main systems, additional information on the facility can be found in [ref. 7].

\subsection{ISP-50 SB-DVI-09 Test Description}

The ISP-50 test began by a rupture in the DVI line, the break has an area equivalent to $50 \%$ of the DVI line. The initial and boundary conditions were based on the sequence of events predicted by code application, during the DVI line break accident for the reference plant (APR1400) and were determined by applying scaling law to the ATLAS [ref. 8-9].

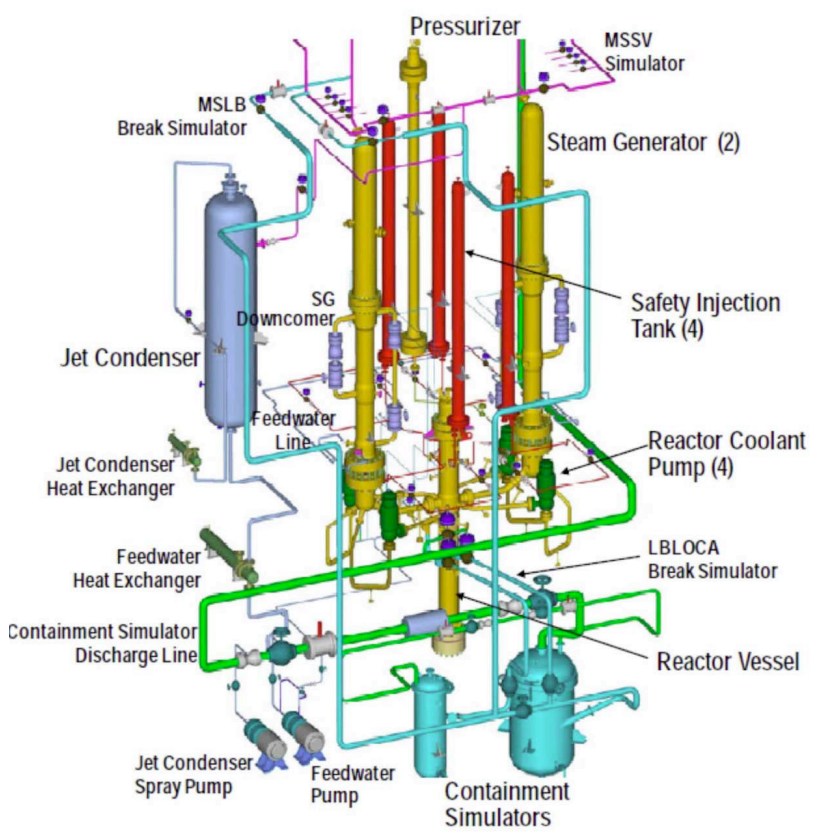

Fig. 1. Configuration of the ATLAS Facility
In the present test, one safety injection pump (SIP-2) was used with the assumption that one of the diesel generators would lose power. Furthermore, the safety injection flow to the broken DVI-4 nozzle was not credited so that the safety injection flow from the safety injection pump (SIP) was only injected through the DVI-2 nozzle opposite to the broken nozzle. Three safety injection tanks (SITs) except for the one connected to the broken DVI-4 nozzle were used to provide the safety injection flow into the downcomer, see Figure 2.

The accident can be subdivided into four main phenomenological windows (Ph.W.):

1. Subcooled blowdown (time from 0 to $190 \mathrm{~s}$ up to the first loop seal clearing);

2. Saturated blowdown and primary to secondary side pressure decoupling (time from $190 \mathrm{~s}$ to minimum primary side mass occurrence at $467 \mathrm{~s}$ );

3. RCS inventory recovery (time from $467 \mathrm{~s}$ to $1236 \mathrm{~s}$ );

4. Plant stabilization (time from $1236 \mathrm{~s}$ to end of the test).

Ph.W. 1). Following the break the primary system pressure rapidly dropped to about $8.2 \mathrm{MPa}$ from its initial pressure of 15.6 MPa; it showed a little oscillation between $57 \mathrm{~s}$ and $197 \mathrm{~s}$, then it decreased again. This oscillation was attributed to the MSSV opening and closure according to their set points (see Figure 3). During this phase flashing occurred in the primary system and most of the primary side inventory approached saturation condition.

A subcooled break flow was observed in the early period of the test. However, the break flow changed rapidly to a saturated break flow and maintained a saturated choking condition during the remaining test period. The break flow rate abruptly dropped to less than $1.0 \mathrm{~kg} / \mathrm{s}$ at $190 \mathrm{~s}$, when the first loop seal clearing occurred, and it continuously decreased during the remaining test period.

At $54 \mathrm{~s}$ the SIP started the injection into the RPV through the DVI-1 nozzle opposite the affected one.

On break, the core water level decreased to the middle of the active zone and the higher increase in the cladding

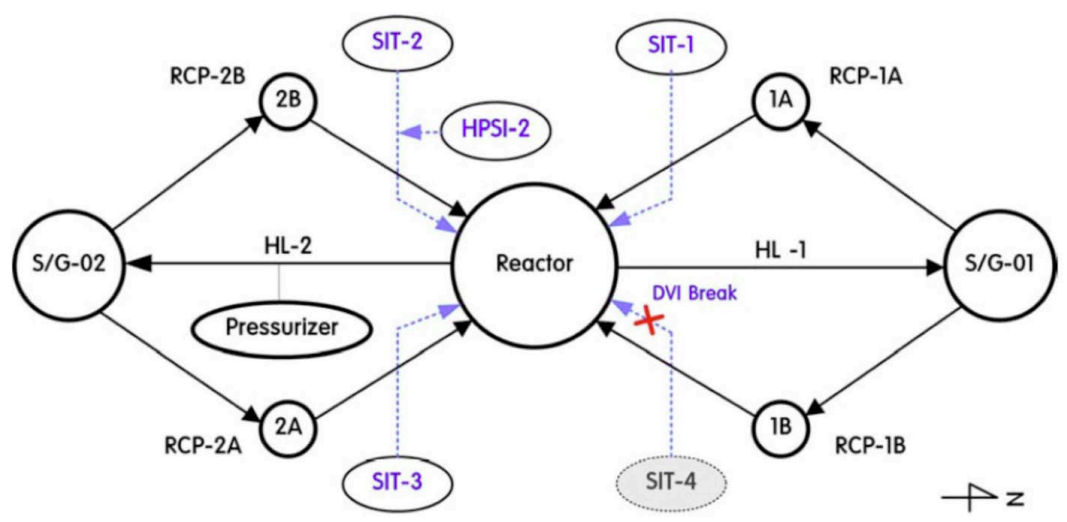

Fig. 2. Arrangement and Labeling of Primary Legs 
temperature was measured near the broken DVI nozzle. When the first loop seal was cleared, the water level recovered (to about $2.2 \mathrm{~m}$ ) and thereafter stabilized at around $2.0 \mathrm{~m}$. The core uncovering period was estimated to be approximately $25 \mathrm{~s}$.

Ph.W. 2). The primary to secondary side pressure decoupling characterizes the phase 2). After the 1st loop seal clearing, the U-tubes of the both steam generators were emptied but the flow passage through the loop 2 was still blocked due to the loop seal formed in the intermediate legs and maintained such a blocked condition until the 2nd loop seal clearing. Thus, the reverse heat transfer in the U-tubes of the steam generator 2 resulted in the increased temperature of the fluid inside the U-tubes, causing an increase in pressure. This temperature increase was confirmed by the measured fluid temperatures inside the ascending and descending U-tubes.

Saturated break mass flow was kept along the Ph.W. 2, the minimum primary side mass and water level in Reactor Pressure Vessel (RPV) occurred before the actuation of SITs.

The cladding temperature showed a non-uniform

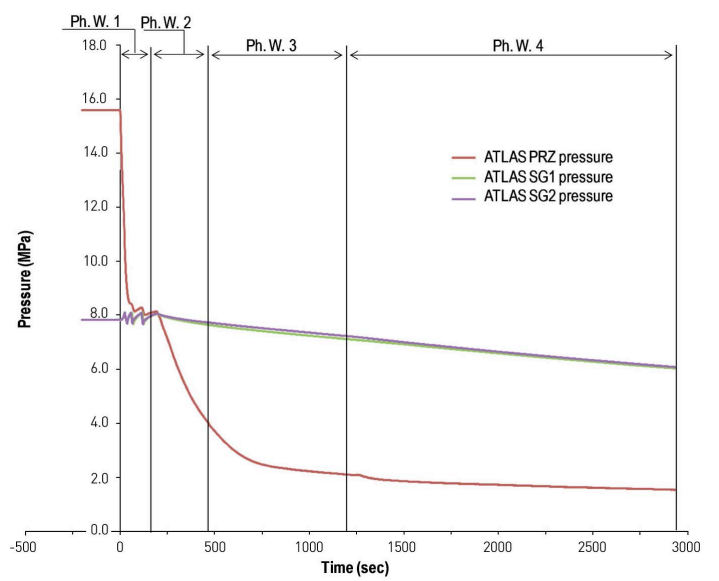

Fig. 3. Measured Primary and Secondary Side Pressures and Identification of $\mathrm{Ph}$. W.
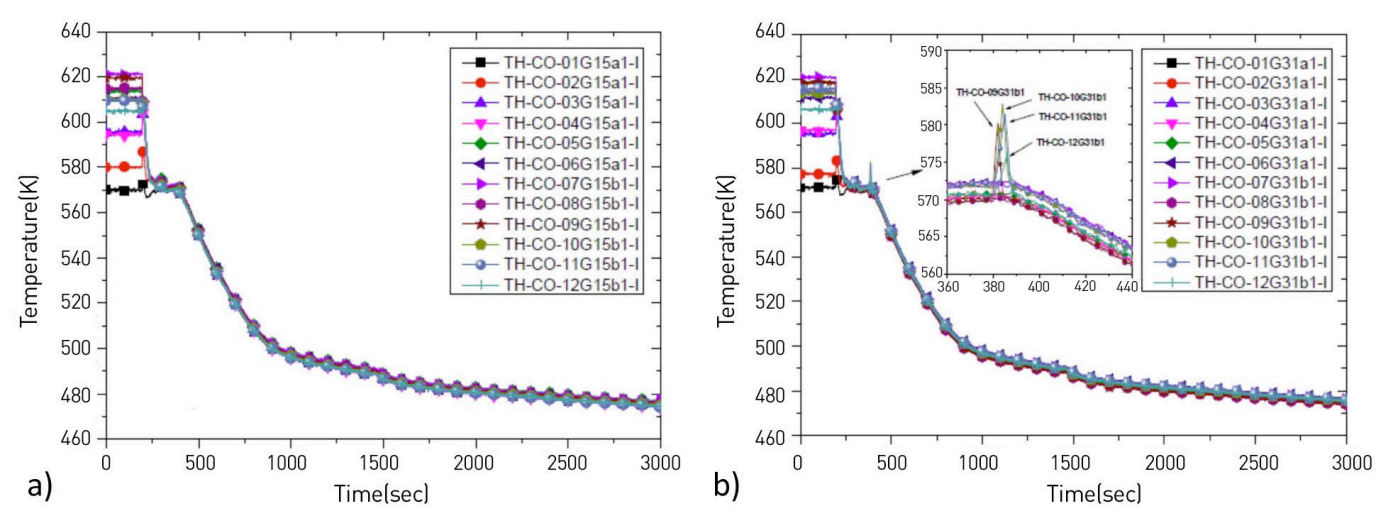

Fig. 4. Measured Peak Cladding Temperature at Different Positions: a) Opposite Side of the Break; b) Near the Break Location

distribution along the radial direction (see Figure 4), the PCT occurred at the top of the core in the group of heater rods closer to the break location.

Ph.W. 3). The third Ph.W. was characterized by SIT intervention and related behaviour. Three SITs started to supply water into the corresponding intact DVI nozzles. When SIT started, the highly sub-cooled water condensed the steam of downcomer rapidly, reducing the downcomer pressure.

The SIT flow rate gradually decreased from 0.05 down to $0.01 \mathrm{~kg} / \mathrm{s}$, but increased again toward the end of the window, due to the second loop seal clearing.

The second loop seal clearing also affected the core water levels but its effect was not so significant compared with the first loop seal clearing (Figure 5). The water level started to rapidly decrease from the time of the first loop seal clearing to the actuation of SITs. The second loop seal clearing caused a sudden decrease in the water level. Afterwards the water level continuously increased during the remaining test period due to ECC water injection.

$\mathrm{Ph}$. W. 4). During this last phase of the transient all main parameters become stable. Decay heat is removed by saturated water or mixture in the top part of the core, being collapsed core level below TAF (Top Active Fuel). Steam is discharged through the break, its integral is fully replaced by safety injection, as demonstrated by the constant trend of the RCS mass inventory as well as collapsed core and downcomer level. No major quantifiable event occurred during the last test time span, thus the experiment was terminated.

\section{ANALYTICAL WORK}

\subsection{Nodalization Description}

The RELAP5 input deck adopted for simulating the ATLAS facility is a nodalization were carried out following the general criteria normally adopted to develop a nodalization; some worth recalling include:

- Limited use of cross flow junction.

NUCLEAR ENGINEERING AND TECHNOLOGY, VOL.44 NO.6 AUGUST 2012 

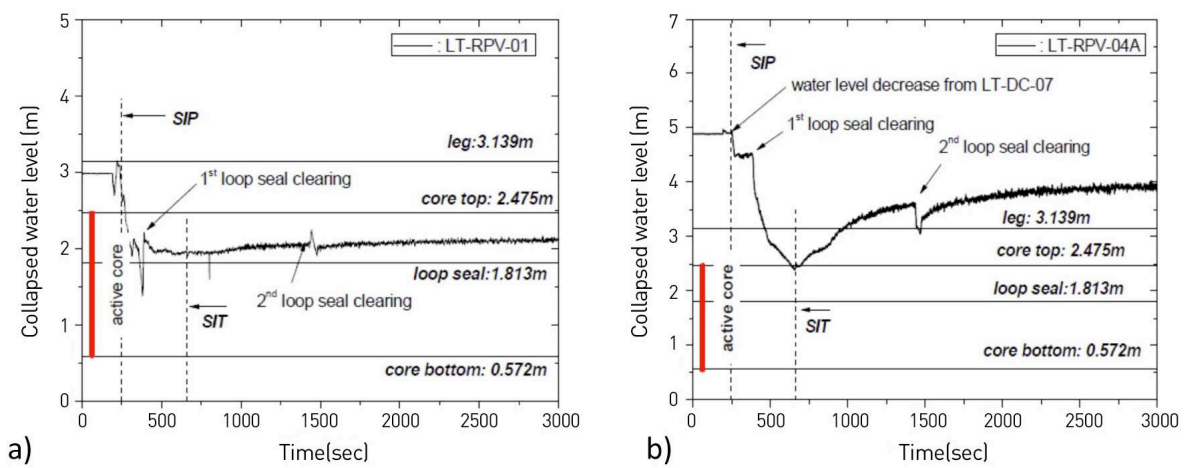

Fig. 5. Measured Collapsed Water Level: a) Core Region; b) RPV Downcomer Region

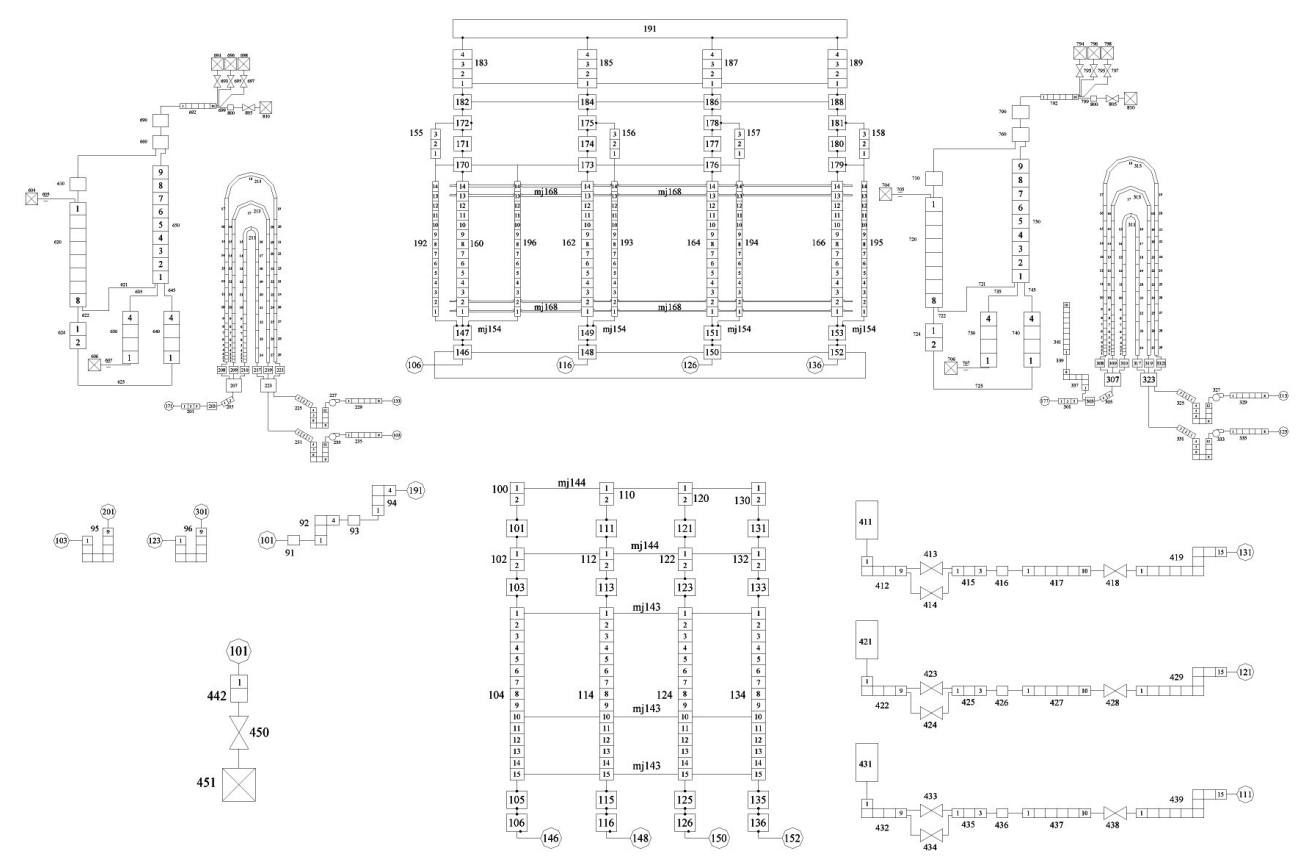

Fig. 6. Sketch of RELAP5 ATLAS Nodalization

- Avoid use of pipe internal junction.

- Slice nodalization technique.

- Avoid loop lumping.

- Ratio between length of two adjacent volumes in the range of 0.7-1.2.

Together with general indications, the rationale adopted for the ATLAS nodalization is based on the ideal division of the RPV into four sectors covering azimuthally an angle of $90^{\circ}$ each. Each sector is thus feed by one cold leg.

The nodalization scheme can be seen in Figure 6 and hereafter a description of the model, divided by major zone or component, is included.

\section{Reactor Pressure Vessel}

The downcomer is subdivided into four parts, each of these represented by a sequence of BRANCH for the bottom and top part and PIPE for the central DC part downward oriented. All components representing each sector are connected by cross flow junctions, defined into a MULTIPLE JUNCTION. The passive DC heat structure is modelled to account for thermal inertia and heat losses. As per the RPV also the lower plenum has been schematized into four sectors, each of these modelled by two BRANCHs and linked by cross flow junctions defined into a MULTIPLE JUNCTION. The passive LP heat structure is modelled to account for thermal inertia and heat losses. The four PIPEs are linked by cross flow junctions defined into a MULTIPLE JUNCTION. The active zone is split into ten subvolumes. The heated flow is collected at the core outlet modelled by four BRANCH components for each radial subdivision and cross-linked for the rest of the core nodalization.

\section{Loops}

The two loops are modelled separately and are identical apart the connection with the surge line at the hot leg 2 . All the loop parts are present in the model, i.e. the hot legs, the SGs, the two intermediate legs, the two pumps (whose homologues curves are taken from [ref. 10]) and the two cold legs. 
Table 1. Check of Volume Distribution within Primary and Secondary Side

\begin{tabular}{c|c|c}
\hline Component & Volume of ATLAS $\left(\mathbf{m}^{3}\right)$ & 0.3823 \\
\hline Core & 0.3840 & 0.1663 \\
\hline Downcomer & 0.1790 & 0.2734 \\
\hline Pressurizer & 0.2720 & 0.0040 \\
\hline PZR surge line & 0.0047 & 0.0245 \\
\hline Hot leg (1 of 2) & 0.0262 & 0.3111 \\
\hline SG (1 of 2) & 0.3066 & 0.0114 \\
\hline Cold leg (1 of 4) & 0.0115 & 0.0159 \\
\hline Int. leg (1 of 4) & 0.0161 & 0.0068 \\
\hline RCP (1 of 4) & 0.0053 & 1.6464 \\
\hline Primary circuit (total) & 1.6366 & $(1.6341$ excluding core guide tubes, \\
\hline SG (1 of 2) & & core-UP bypass, DC-UH head byass) \\
\hline Steam line (1 of 2) & 1.3330 & 1.171 \\
\hline Secondary circuit (total) & $0.0862 *$ & 0.0681 \\
\hline
\end{tabular}

\section{Steam generator}

The primary side of the steam generator is modelled by an inlet plenum (BRANCH) which is further subdivided into three parallel BRANCHs, each of these feeding a PIPE representing the U-tube. The U-tube bundle is thus schematized by three equivalent PIPEs having different length and elevation and grouping 41, 73 and 62 real Utubes respectively. The outlet steam generator plenum follows the same approach of the inlet plenum.

The steam generator secondary side represents the main parts taking into consideration the flow path and related recirculation. The downcomer is modelled by a PIPE downward oriented in which the feedwater is injected (not in the present test). Part of the feedwater (if injected) mixed with the saturated water coming from the separator, goes directly into the riser zone modelled by a PIPE too. The rest of the feedwater goes into the economizer zone modelled by two parallel PIPEs, one of these is directly fed by the feedwater pump simulator. The steam separation is modelled by a SEPARATOR component, the steam line is modelled including the relief and safety valves by MOTOR VALVE. Finally the turbine stop valve links the steam line to a TIME DEPNDENT VOLUME, which constitutes the boundary condition (in terms of pressure) for the secondary side.

\section{Pressurizer and surge line}

The pressurizer is modelled by a PIPE component having ten subvolumes, it is connected via the surge line represented by a PIPE too, to the hot leg 2.

Passive heat structures are defined to account for the heat losses and the thermal inertia of the component both in the spherical and cylindrical sections.

\section{Safety injection line}

The safety injection lines that link the safety injection tanks to the downcomer are fully modelled including the valves aimed at simulate the two behaviour of the SIT discharge, i.e. the fluidic device behaviour. Three safety injection lines are modelled, by PIPE and BRANCH components. The fourth is not present because of the presence of the break device.

\section{Main flow bypass}

Both downcomer to upper head and downcomer to hot legs bypasses are modelled, connecting valves are not present in the nodalization rather a restricted flow area and a $\mathrm{k}$ loss coefficient are set to adjust the mass flow rate.

\subsection{Nodalization Qualification and Steady State Achievement}

Once a nodalization has been set up, a deep check shall be conducted in order to verify its geometrical fidelity and its capability in predicting a correct steady state reference conditions. University of Pisa developed a procedure called nodalization qualification [ref. 1] which is based on two major steps: steady state qualification; on transient qualification. The former step includes various checks such as: geometrical verification, check of pressure drops along the loop, volume vs. height curve, etc. Selected checks are reported in Table 1 and Figure 7.

The latter step implies the availability of an experiment 
which can be used as verification of nodalization capabilities in reproducing thermal-hydraulic phenomena observed in

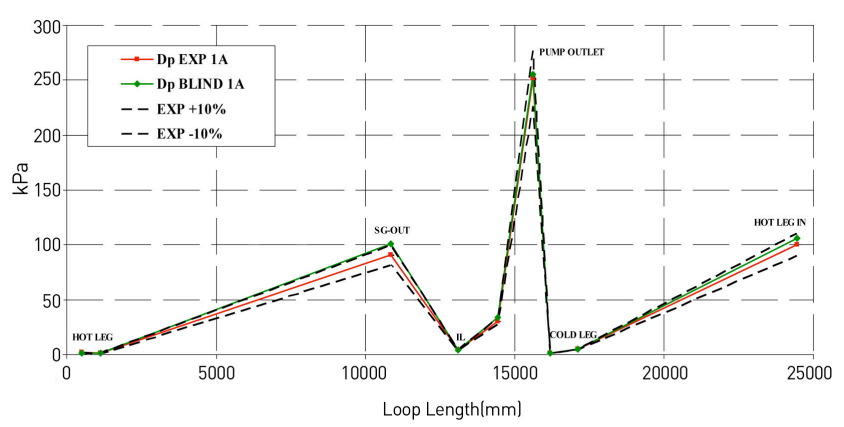

Fig. 7. Pressure Drop vs. Length, Loop 1A the concerned ITF. Being the SB-DVI-09 the first transient conducted at ATLAS simulated by UNIPI, this step has not been carried out before ISP-50 simulation.

The steady state results for the two phases have been achieved after $1000 \mathrm{~s}$ of "null transient" calculation in order to stabilize the system. A systematic comparison between experimental and calculated data, for the blind and open phases, concerning steady state condition, together with the related error in percentage has been done, an excerpt is shown in Table 2.

\subsection{Blind and Open Phase Code Results: Qualitative Accuracy Evaluation}

A comparison between measured and calculated data was performed with the objective to verify the capabilities of the code to reproduce the relevant thermal-hydraulic

Table 2. ATLAS ISP-50 Steady State Results for Blind and Open Calculations (Selected Items)

\begin{tabular}{|c|c|c|c|c|c|c|}
\hline Variable & Unit & Exp. & Calc. BLIND & Err. (\%) BLIND & Calc. OPEN & Err.(\%) OPEN \\
\hline Core power & $\mathrm{W}$ & $1.64 \mathrm{E}+06$ & $1.64 \mathrm{E}+06$ & $0.01 \%$ & $1.64 \mathrm{E}+06$ & $0.01 \%$ \\
\hline PRZ pressure & $\mathrm{Pa}$ & $1.56 \mathrm{E}+07$ & $1.55 \mathrm{E}+07$ & $0.79 \%$ & $1.56 \mathrm{E}+07$ & $0.06 \%$ \\
\hline Core inlet temp. & $\mathrm{K}$ & 563 & 562.1 & $0.17 \%$ & 561.9 & $0.20 \%$ \\
\hline Core outlet temp. & $\mathrm{K}$ & 598.1 & 594.8 & $0.55 \%$ & 596.6 & $0.26 \%$ \\
\hline CL1A flow rate & $\mathrm{kg} / \mathrm{s}$ & 2.178 & 2.153 & $1.14 \%$ & 2.031 & $6.77 \%$ \\
\hline CL1B flow rate & $\mathrm{kg} / \mathrm{s}$ & 2.067 & 2.156 & $4.33 \%$ & 2.042 & $1.19 \%$ \\
\hline CL2A flow rate & $\mathrm{kg} / \mathrm{s}$ & 2.313 & 2.152 & $6.94 \%$ & 2.033 & $12.12 \%$ \\
\hline CL2B flow rate & $\mathrm{kg} / \mathrm{s}$ & 2.108 & 2.156 & $2.25 \%$ & 2.027 & $3.83 \%$ \\
\hline PZR level & $\mathrm{m}$ & 3.359 & 3.11634 & $7.22 \%$ & 3.30962 & $1.47 \%$ \\
\hline SG1 pressure & $\mathrm{Pa}$ & $7.83 \mathrm{E}+06$ & 7836770 & $0.09 \%$ & $7.83 \mathrm{E}+06$ & $0.02 \%$ \\
\hline SG2 pressure & $\mathrm{Pa}$ & $7.83 \mathrm{E}+06$ & 7835960 & $0.10 \%$ & $7.83 \mathrm{E}+06$ & $0.04 \%$ \\
\hline SG1 level & $\mathrm{m}$ & 2.03 & & - & 2.0025 & 0.027 \\
\hline SG2 level & $\mathrm{m}$ & 1.97 & & - & 2.00557 & 0.035 \\
\hline Heat removal SG1 & $\mathrm{W}$ & 754662 & 769662 & $1.99 \%$ & 772940 & $2.42 \%$ \\
\hline Heat removal SG2 & $\mathrm{W}$ & 759245 & 780602 & $2.81 \%$ & 786125 & $3.54 \%$ \\
\hline SIT pressure & $\mathrm{Pa}$ & $4.19 \mathrm{E}+06$ & $4.19 \mathrm{E}+06$ & $0.03 \%$ & $4.19 \mathrm{E}+06$ & $0.03 \%$ \\
\hline SIT2 pressure & $\mathrm{Pa}$ & $4.21 \mathrm{E}+06$ & $4.19 \mathrm{E}+06$ & $0.47 \%$ & $4.19 \mathrm{E}+06$ & $0.47 \%$ \\
\hline SIT3 pressure & $\mathrm{Pa}$ & $4.23 \mathrm{E}+06$ & $4.19 \mathrm{E}+06$ & $0.87 \%$ & $4.19 \mathrm{E}+06$ & $0.87 \%$ \\
\hline SIT1 temp. & $\mathrm{K}$ & 323.9 & 323.2 & $0.22 \%$ & 323.2 & $0.22 \%$ \\
\hline SIT2 temp. & $\mathrm{K}$ & 323.5 & 323.2 & $0.09 \%$ & 323.2 & $0.09 \%$ \\
\hline SIT3 temp. & $\mathrm{K}$ & 323 & 323.2 & $0.06 \%$ & 323.2 & $0.06 \%$ \\
\hline RWT temp. & $\mathrm{K}$ & 368.21 & 373.12 & $1.33 \%$ & 373.12 & $1.33 \%$ \\
\hline Containment pressure & $\mathrm{Pa}$ & $1.03 \mathrm{E}+05$ & $1.01 \mathrm{E}+05$ & $1.62 \%$ & $1.01 \mathrm{E}+05$ & $1.62 \%$ \\
\hline
\end{tabular}


phenomena observed in the experiment, including multidimensional behaviour. The analysis allows also verifying the correctness of the imposed boundary conditions.

The reference calculations related to blind and open phases are labelled "BLIND" and "OPEN", respectively. The qualitative analysis reported hereafter starts with Table 3 in which the resulting sequence of main events for both calculations compared with the experiment is reported. It can be seen that the timing of major events are quite well matched in the code runs apart loop seal clearing, especially the one occurring in loop 2.

The analysis of the two code runs, one for the blind and one for the open phase, are performed by means of a comprehensive comparison between measured and calculated trends or values, examples are given in Figure
8 and Figure 9 in which primary pressure and break mass flow are reported. It can be seen that the code reasonably reproduce the transient, open calculation is closer to the measured data, although blind run was acceptable.

The ATLAS facility instrumentation is capable of providing a comprehensive map of the fluid temperature distribution of the downcomer region. A grid of thirty-six thermocouples are installed distributed at six different elevations and at six different azimuthal locations. Figure 10 shows the comparison between measured data and open calculation results of azimuthal fluid temperature distribution at middle downcomer elevation. The code does not predict the mixing inside the downcomer, rather a strong temperature decrease appears in correspondence of DVI 2 nozzle.

Table 3. ATLAS test ISP-50: Resulting Sequence of Main Events

\begin{tabular}{|c|c|c|c|c|}
\hline \multicolumn{2}{|l|}{ EVENT } & EXP. (s) & BLIND (s) & OPEN (s) \\
\hline \multicolumn{2}{|l|}{ Break valve open } & 0.0 & 0.0 & 0.0 \\
\hline \multicolumn{2}{|l|}{ MSSVof SG-2 open ( $1^{\text {st }}$ opening $)$} & 24.0 & 28.0 & 23.0 \\
\hline \multicolumn{2}{|l|}{ MSSVof SG-1 open ( $1^{\text {st }}$ opening) } & 24.0 & 28.0 & 23.0 \\
\hline \multicolumn{2}{|l|}{ Low pressurizer pressure trip (LPP) } & 25.0 & 24.0 & 26.5 \\
\hline \multicolumn{2}{|l|}{ Main steam isolation } & 25.0 & 24.0 & 22.0 \\
\hline \multicolumn{2}{|l|}{ RCPs trip } & 25.0 & 0.0 & 0.0 \\
\hline \multicolumn{2}{|l|}{ Pressurizer emptied } & 26.0 & 19.0 & 23.0 \\
\hline \multicolumn{2}{|l|}{ Main feedwater isolation } & 32.0 & 31.0 & 33.0 \\
\hline \multicolumn{2}{|l|}{ Core power starts to decay } & 33.0 & 24.0 & 33.0 \\
\hline \multicolumn{2}{|l|}{ SIP-2 injection } & 54.0 & 52.0 & 55.0 \\
\hline \multicolumn{2}{|l|}{ MSSV of SG-2 open ( $2^{\text {nd }}$ opening) } & 57.0 & 56.0 & 62.0 \\
\hline \multicolumn{2}{|l|}{ MSSV of SG-1 open ( $2^{\text {nd }}$ opening) } & 62.0 & 56.0 & 62.0 \\
\hline \multicolumn{2}{|l|}{ MSSV of SG-2 open ( $3^{\text {rd }}$ opening) } & 113.0 & 100.0 & 106.0 \\
\hline \multicolumn{2}{|l|}{ MSSV of SG-1 open ( $3^{\text {rd }}$ opening) } & 118.0 & 100.0 & 106.0 \\
\hline \multirow[t]{2}{*}{ Occurrence of minimum core level } & First & 187 & 157 & 176 \\
\hline & Second & 607 & 690 & 594 \\
\hline \multicolumn{2}{|l|}{ Break two phase flow } & 195.0 & 160.0 & 190.0 \\
\hline \multirow[t]{2}{*}{$1^{\text {st }}$ loop seal clearing } & $1 \mathrm{~A}$ & 190.0 & 150.0 & 180.0 \\
\hline & $1 \mathrm{~B}$ & 190.0 & 150.0 & $\mathrm{x}$ \\
\hline \multicolumn{2}{|l|}{ Primary-Secondary pressure reversal } & 207.0 & 170.0 & 192.0 \\
\hline \multicolumn{2}{|l|}{ Separation of SG-1 and SG-2 } & 230.0 & -- & 230.0 \\
\hline \multicolumn{2}{|l|}{ SIT actuation } & 468.0 & 401.0 & 469.0 \\
\hline $2^{\text {nd }}$ loop seal clearing & $2 \mathrm{~B}$ & 1236.0 & 150.0 & 184.0 \\
\hline Test stops & & 2933.0 & 3000.0 & 2500 \\
\hline
\end{tabular}




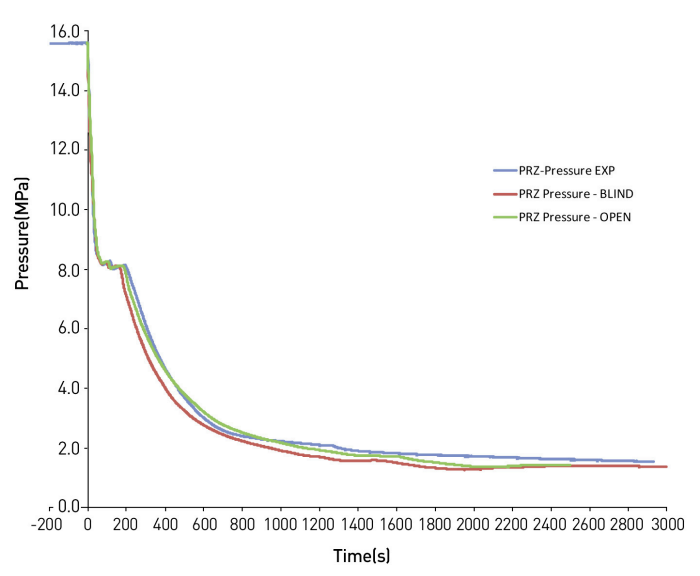

Fig. 8. Primary System Pressure: Comparison between Experiment, Blind and Open Calculations

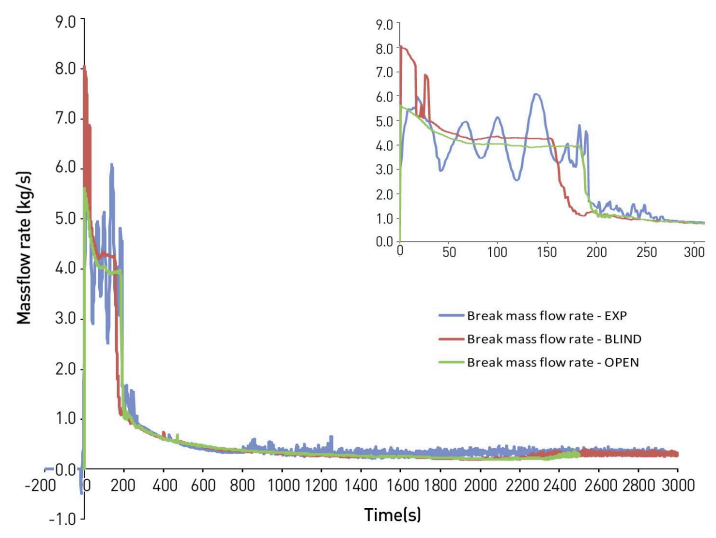

Fig. 9. Break Mass Flow Rate: Comparison between Experiment, Blind and Open Calculations



b) Azimuthal angle of 180 and 240

a) Azimuthal angle of 60 and 120

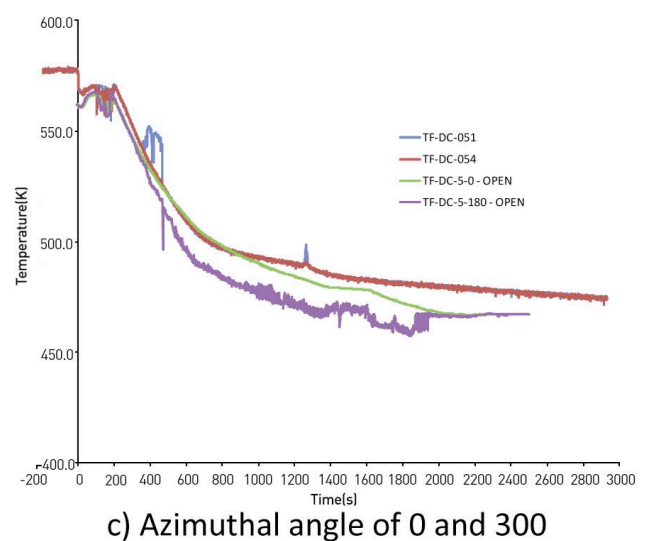

Fig. 10. Azimuthal Distribution of DC Fluid Temperature at Level 5: Comparison between Experiment and Open Calculation

To complement the graphical comparison between code runs and the experimental evidence, the qualitative accuracy evaluation (an analysis method systematically adopted at the University of Pisa [ref. 11]) has been performed. The qtualitative accuracy evaluation showed that the blind calculation resulted in a general key phenomena replication although some minimal predictions appear. The judgement minimal is used by the analyst if one or more phenomena are not predicted by the code, but the reason is understood. . Regarding the open calculation, it showed a better experimental agreement than the blind but still without reproduction observed 3D phenomena. The qualitative evaluation is summarized by tables in which all Relevant Thermal-Hydraulic Aspects (RTA) observed in the experiment are reported and characterized either by related timing or integral or derivative parameters. 
Table 4. Application of FFTBM to Blind and Open Code Runs

\begin{tabular}{|c|c|c|c|c|}
\hline \multirow{2}{*}{ PARAMETER } & \multicolumn{2}{|c|}{ BLIND } & \multicolumn{2}{|c|}{ OPEN } \\
\hline & $\mathbf{A A}$ & WF & $\mathbf{A A}$ & WF \\
\hline Core power & 0.080 & 0.043 & 0.007 & 0.222 \\
\hline Pressurizer pressure & 0.078 & 0.044 & 0.049 & 0.06 \\
\hline SG-1steam dome pressure & 0.209 & 0.08 & 0.164 & 0.096 \\
\hline SIT-01 pressure & 0.171 & 0.05 & 0.113 & 0.079 \\
\hline Core intel temperature & 0.053 & 0.066 & 0.046 & 0.087 \\
\hline Core outlet temperature & 0.039 & 0.037 & 0.035 & 0.063 \\
\hline Hot leg 1 flow rate & 1.817 & 0.222 & 1.979 & 0.243 \\
\hline Hot leg 2 flow rate & 2.619 & 0.217 & 2.810 & 0.242 \\
\hline Active SIT-01 flow rate & 1.503 & 0.175 & 1.280 & 0.191 \\
\hline Active SIP-02 flow rate & 0.323 & 0.136 & 0.295 & 0.166 \\
\hline Total break flow rate & 0.882 & 0.145 & 0.630 & 0.186 \\
\hline Accumulated break mass & 0.060 & 0.066 & 0.044 & 0.102 \\
\hline Down-comer level & 0.610 & 0.083 & 0.594 & 0.087 \\
\hline Active core region level & 0.659 & 0.131 & 0.641 & 0.147 \\
\hline Pressurizer level & 0.181 & 0.073 & 0.088 & 0.101 \\
\hline Collapsed water level IL1A & 0.523 & 0.054 & 0.396 & 0.082 \\
\hline Collapsed water level IL1B & 0.976 & 0.082 & 1.283 & 0.083 \\
\hline Collapsed water level IL2A & 1.200 & 0.1 & 1.880 & 0.104 \\
\hline Collapsed water level IL2B & 0.796 & 0.078 & 0.745 & 0.086 \\
\hline Clad temperature at region 2 & 0.049 & 0.066 & 0.043 & 0.093 \\
\hline Clad temperature at region 7 & 0.042 & 0.056 & 0.037 & 0.065 \\
\hline Clad temperature at region 12 & 0.075 & 0.082 & 0.041 & 0.085 \\
\hline TOTAL AVG. ACCURACY & 0.311 & 0.0730 & 0.314 & 0.0957 \\
\hline
\end{tabular}

\subsection{Blind and Open Phase Code Results: Quantitative Accuracy Evaluation}

The quantitative accuracy evaluation is performed by the use of the FFTBM (Fast Fourier Transform Based Method). The method is applied to the transient as a whole. Table 4 summarizes the results for the "blind" and "open" calculation. 22 parameters have been selected [ref. 12] including data that provide a broader view of the test evolution.

The following comments derive from the analysis of the results; both blind and open calculations show general positive results for primary and secondary pressure and fluid temperature. The worst data attained was to the hot leg flow rates because of their oscillatory trends (confirmed by a high WF value). Open calculation is generally improved (although total average accuracy are practically equally between the two runs) as come from accumulated break mass flow and pressurizer level comparison.

\section{CONCLUSION}

The present paper deals with the work performed at the University of Pisa in the frame of the International Standard Problem 50, which was based on a SBLOCA test conducted at the ATLAS facility. The test simulates the break of the DVI line No. 4. The University of Pisa participated in both phases of the ISP-50, submitting both 
blind and open calculation results.

To submit the mentioned contribution a nodalization have been set up, taking into consideration the possible $3 \mathrm{D}$ phenomena occurring in the concerned test, and qualified according to the internal procedure which includes two major steps. A systematic check of steady state results have been done, and after acceptable agreement have been reached the simulations were performed. Adopted code was RELAP5Mod3.3, run in a PC Windows XP based.

Comparing code results with experimental data the following can be stated:

- The code correctly predicts the general test behavior and both blind and open runs were acceptable.

- Three-dimensional phenomena observed were not replicated by the code. Namely downcomer mixing was largely underestimated and unequal radial clad temperature distribution was not predicted. Notwithstanding the fictitious three dimensional nodalization solution, the lack of a specific model inside the code for this kind of phenomena can be identified as the reason for such less accurate simulation.

The code accuracy has been assessed from qualitative and quantitative viewpoints. The latter by the application of the FFTBM algorithm, a tool able to give an overall figure of merit of the calculations. FFTBM has been applied to both blind and open calculations, confirming the general good replication of the concerned experiment.

\section{REFERENCES}

[ 1 ] M. Bonuccelli, F. D’Auria, N. Debrecin, G.M. Galassi “A methodology for the qualification of thermalhydraulic code nodalizations", NURETH-6 Grenoble (F) 5-8 October 1993.

[2] A. Prosek, F. D'Auria, B. Mavko, 'Review of Quantitative Accuracy Assessments with Fast Fourier Transform Based
Method (FFTBM)," Nuclear Engineering and Design, 217, 179 (2002).

[ 3 ] F. D'Auria, M. Leonardi, R. Pochard, "Methodology for the evaluation of thermalhydraulic codes accuracy" Proc. Int. Conf. on New trends in Nuclear System Thermohydraulics, Pisa, pp. 467-477, 1994.

[4] W.P. Baek, C.-H. Song, B.J. Yun, T.S. Kwon, S.K. Moon and S.J. Lee, "KAERI Integral Effect Test Program and the ATLAS Design”, Nuclear Technology, 152, 183-195 (2005).

[ 5 ] W.P. Baek and Y.S. Kim, "Accident Simulation ATLAS for APWRs", Nuclear Engineering International, 53, 21-25 (2008).

[6] M. Ishii, S. T. Revankar, T. Leonardi, R. Dowlati, M. L. Bertodano, et al. "The Three Level Scaling Approach with Application to the Purdue University Multidimensional Integral Test Assembly (PUMA)", Nucl. Eng. Des., 186, 177 (1998).

[ 7 ] K. Y. Choi, Y. S. Kim, C. H. Song, and W. P. Baek "Major Achievements and Prospect of the ATLAS Integral Effect Tests" Science and Technology of Nuclear Installations Vol. 2012 (2012), Article ID 375070.

[8 ] K. Y. Choi et al., "Detailed Information on Actual Test Conditions and Procedures for ISP-50", KAERI Interim report (2009).

[9] K. Y. Choi et al., "ISP-50 Specifications for a Direct Vessel Injection Line Break Test with the ATLAS", KAERI/TR3778 (2009).

[10] K.H. Kang et al., "ATLAS Facility and Instrumentation Description Report”, KAERI/TR-3779, (2009).

[11] A. Del Nevo, D. Araneo, M. Cherubini, F. D'Auria, G. M. Galassi "Analysis of SBLOCA - counterpart test - in PSBVVER facility by Cathare2: quantitative/qualitative accuracy evaluation and comparison with Relap5 code" International Conference On Nuclear Engineering ICONE-13, Beijing (China), May 16-20, 2005.

[12] OECD/NEA "International Standard Problem No. 50" Final Integration report Voll. I-III, February 2012, NEA/CSNI/R (2012)6. 